\begin{tabular}{ccc}
\hline & International Journal of Engineering \& Technology, $7(4.1)(2018) 94-98$ \\
SPC & International Journal of Engineering \& Technology \\
\hline
\end{tabular}

\title{
Performance Assessment for Mobile Base Station in UNITEN Vicinity
}

\author{
Mohamad Nazri*, Goh Chin Hock, Nurzanariah Roslan, Saidatul Hamidah, Nayla Ferdous \\ Institute of Sustainable Energy, Universiti Tenaga Nasional Kajang, Malaysia \\ *Corresponding author E-mail: mohamad.nazri@uniten.edu.my
}

\begin{abstract}
This paper present the study at Received Signal Code Power (RCSP) and energy per chip divided by the total in-band interference (Ec/No) these parameters in order to provide good quality service to customers, mobile operator perform benchmarking project to monitor their quality of service which deliver to customer. The relation between these two parameters were discussed and proved from the drive test result at UNITEN vicinity. The method that used in this research was Network Planning Process and Data verification process. The fabrication and verification of data was done by using NEMO HANDY tools and HATA model. The aim is to carry out the test and research the Base Transceiver Station for mobile operation functionally and quality also collect the data and generate the report regarding the quality of voice call, call attempts, call fail, data network, attempt, data of RCSP and EC/No of the mobile operator. The result showed that the Telco B provide the best $3 \mathrm{G}$ service among the competitor and Telco D provide the $2 \mathrm{G}$ service compare the other operator. The relationship between RCSP and EC/No in path loss calculation is directly proportional to each other are proven. Besides that, it also proves that the terrain contour, site environment and antenna height will affect the throughput of the antenna transmitting power for mobile base station.
\end{abstract}

Keywords: Drive test; Ec/No; Optimization; RCSP; RF planning.

\section{Introduction}

The operators throughout the world have faced the same four challenges that are faced repeatedly: 1) sub-optimal RF optimization, 2) trouble to tune the RF parameters, 3) increasing the reliability of inter-system transition and 4) better in building coverage [1]. The RF plan of a cellular communication system revolves around two principle objectives; Coverage and Capacity Coverage relate to the geographical footprint within the system that has sufficient RF signal strength to provide for a call/data session [2].

Mobile operators have that started and quality of services for this network performance. In this research, the relationship between the parameter of RCSP and Ec/No with the drive test has carried out. The drive test for Logfiles collecting fot four mobile operators in Malaysia which are Telco A, Telco B, Telco C and Telco D has also verified. The aim of this research is to optimize the relationship between the parameters of RCSP and EC/No with the Base Transceiver Station (BTS) or cell site for the RF network planning [3].

\section{Experiment Description}

For simplicity, the network planning process started with pre-planning, planning detailed planning, site verification and optimization [4]. The planning and verification is the stage which drive test takes over. As shown in Figure 1, during planning stage, drive test

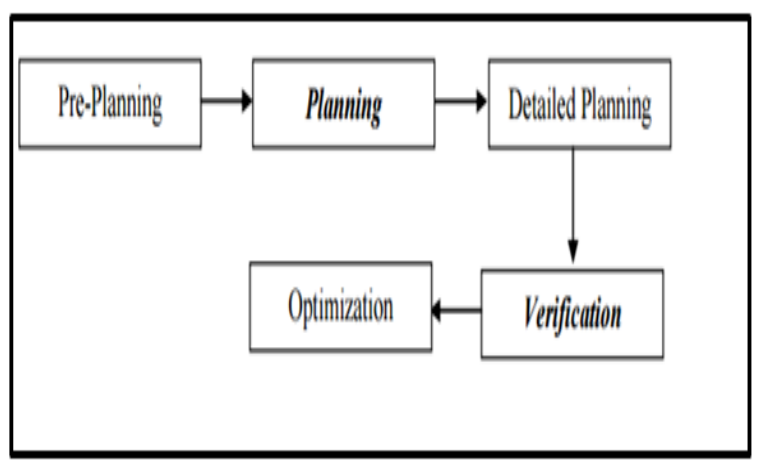

Fig. 1: Network process

survey has done. After detailed planning, verification of parameter and quality are archived the Key Performance Indicators (KPIs). As shown in Figure 2 and Figure 3 below, drive test was made around UNITEN area to collect the voice and data log files also research the transceiver station of operators in UNITEN area. 


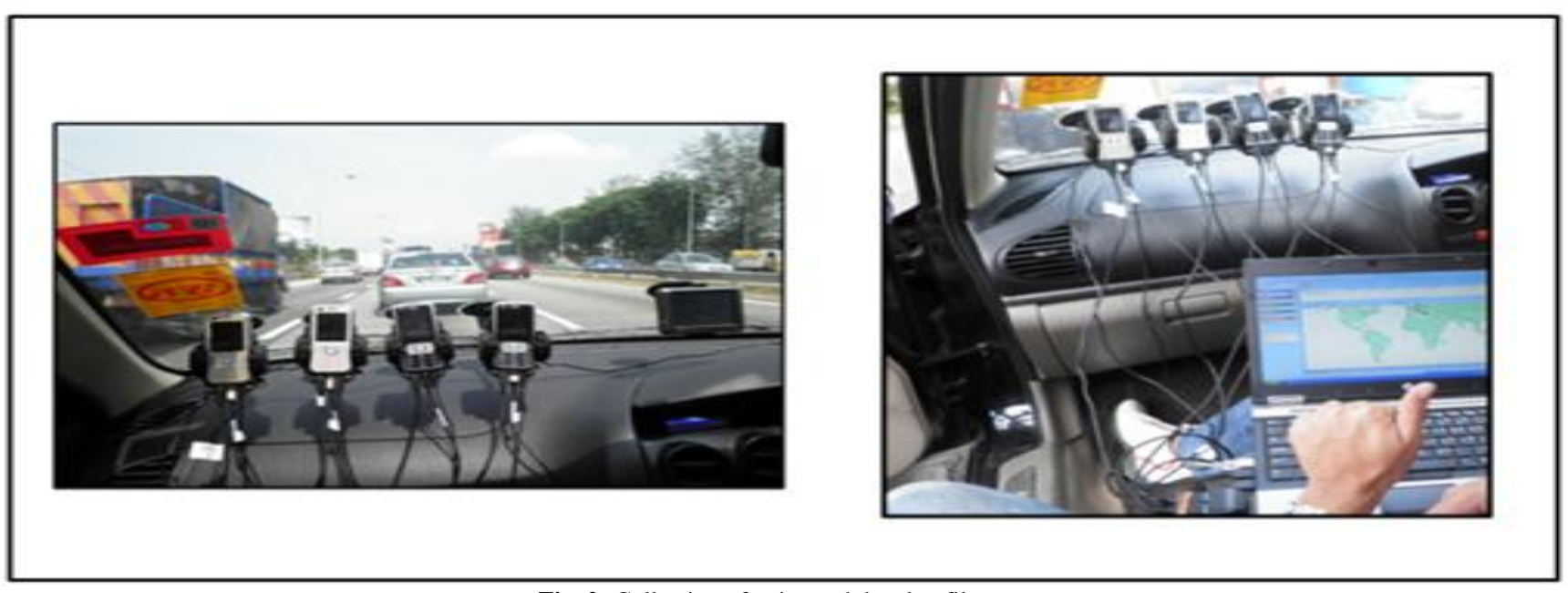

Fig. 2: Collection of voice and data log files

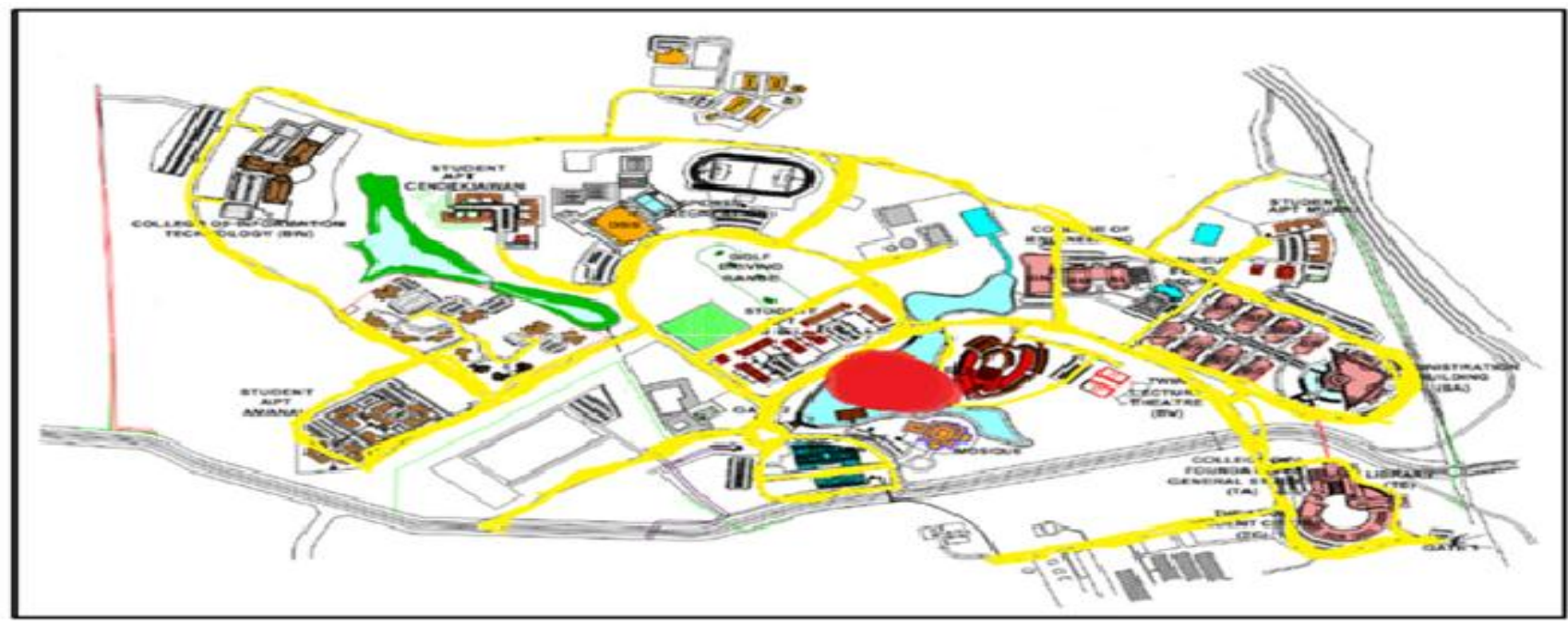

Fig. 3: Drive test route

A Nemo Handy consist of a Nokia N80 test mobile with the Nemo Handy Software, a Bluetooth receiver and Nemo Handy file converter software [5]. All network parameters supported by the Nemo tool [6]. Signaling message is stored in the Handy log file and available for post processing.

\subsection{Hata model}

Hata model is formulated with the measurement data from Okumura model. This model is widely a adopted is urban area type and its frequency application ranges is from 150 to $1500 \mathrm{MHz}$, the height of the antenna at the base station is from 30 to 300 meters and reaching distance is within 1 to $20 \mathrm{~km}$ range.

The propagation loss is calculated by using this model and as per shown below:

$P L=69.55+26.16 \log (f)-13.82 \log (h t)-a(h m)+[44.9-6.55$ $\log (\mathrm{ht})] \log (\mathrm{d}) \mathrm{dB}$

\begin{tabular}{|l|l|}
\hline $\mathrm{f}$ & Operating frequency (MHZ) 2100 \\
\hline $\mathrm{ht}$ & Transmitting station antenna height \\
\hline $\mathrm{hm}$ & Mobile unite antenna height $(\mathrm{m})$ \\
\hline $\mathrm{a}(\mathrm{hm})$ & Correction factor for mobile unit antenna height \\
\hline $\mathrm{d}$ & Distance from transmitting station \\
\hline
\end{tabular}

$\mathrm{a}(\mathrm{hm})=[1.1 \log (\mathrm{f})-0.7] \mathrm{hm}-[1.56 \log \mathrm{f}-0.8] \mathrm{dB}$

$$
\begin{array}{ll}
\mathrm{f} & =2100 \mathrm{MHz} \\
\mathrm{ht} & =2 \mathrm{~m} \\
\mathrm{hm} & =1 \mathrm{~m} \\
\mathrm{~d} & =100 \mathrm{~m}, \mathrm{a}(\mathrm{hm})=391 \mathrm{~dB} \\
\mathrm{~d} & =500 \mathrm{~m}, \mathrm{a}(\mathrm{hm})=421 \mathrm{~dB} \\
\mathrm{~d} & =1000 \mathrm{~m}, \mathrm{a}(\mathrm{hm})=434 \mathrm{~dB} \\
\mathrm{~d} & =1500 \mathrm{~m}, \mathrm{a}(\mathrm{hm})=442 \mathrm{~dB} \\
\mathrm{~d} & =2000 \mathrm{~m}, \mathrm{a}(\mathrm{hm})=447 \mathrm{~dB}
\end{array}
$$

Actual calculation for path loss has completed by Hata Model for certain area at in UNITEN. Table 1 below shows the distance between the transmitting antenna and mobile antenna and their prospectively path loss output.

Table 1. Distance and the path loss

\begin{tabular}{|c|c|c|}
\hline Area & Distance & PL (dBm) \\
\hline COE & $100 \mathrm{~m}$ & 55.92 \\
\hline ILMU & $300 \mathrm{~m}$ & 56.24 \\
\hline MPH & $500 \mathrm{~m}$ & 56.37 \\
\hline ILSAS & $750 \mathrm{~m}$ & 56.44 \\
\hline COIT & $1500 \mathrm{~m}$ & 56.51 \\
\hline
\end{tabular}

The result computed after substituting the value into the Hata model formula. The Figure 4 below explained the output of the path loss 
according to the data distance collected by drive test route. Obviously, the pass loss is directly proportional to the distance between transmitter and receiver.

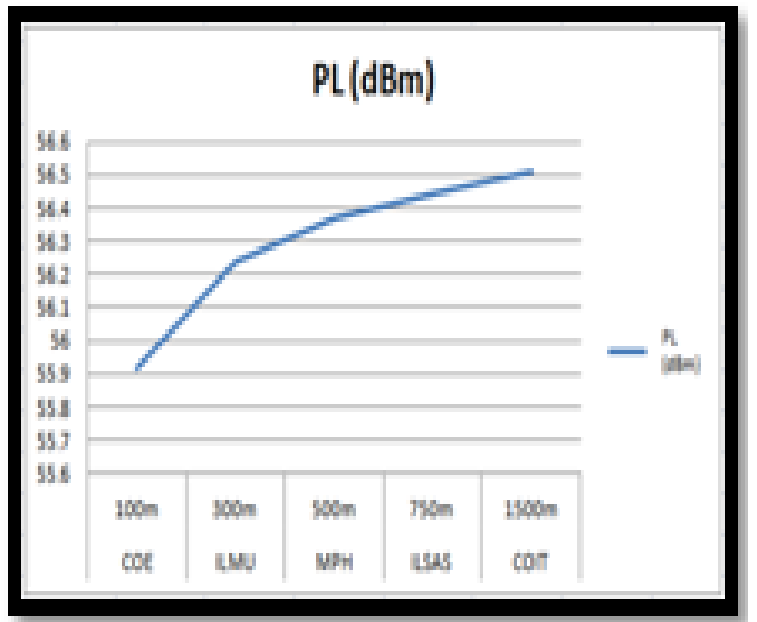

Fig. 4: Graph path loss data

\section{Result and analysis}

In the result, here are 3 types of colour used to identify the strength an $d$ the quality of the RCSP and Ec/No signal which are green, yellow and blue colour. The green colour signal indicated the RCSP quality is good. The range of the good RCSP is greater than $-85 \mathrm{dBm}$. The moderate signal is in yellow colour. The range of the moderate RCSP is between $-85 \mathrm{dBm}$ to $-95 \mathrm{dBm}$. The red colour signal indicated the RCSP quality is bad. The RCSP quality will consider bad when the signal is smaller than $-95 \mathrm{dBm}$.
Again , in Ec/No signal the green colour indicated the best quality of $\mathrm{Ec} / \mathrm{No}$ signal which is in the range of 0 to $-8 \mathrm{dN}$. Yellow colour indicated the moderate quality of Ec/No signal which is range of $8 \mathrm{~dB}$ to $-12 \mathrm{~dB}$. The bad quality of $\mathrm{Ec} / \mathrm{No}$ signal is in range of $-12 \mathrm{~dB}$ to $-14 \mathrm{~dB}$ which is in red colour. At last but not least, the blue colour indicated the worst quality of Ec/No signal which is in the range of $-14 \mathrm{~dB}$ to $-34 \mathrm{~dB}$.

\subsection{Telco A}

There are 813 sample of signals has been generated during the entire drive test. In these 813 samples, $64.28 \%$ is in good quality RCSP signal, $32.02 \%$ is in moderate RCSP signal and only $3.70 \%$ is in bad quality of RCSP signal. This shown the quality of RCSP parameter is good in Telco A operator. From the generated map, there are different colour been plot along the drive test route. The bad quality of RSCP signal only occurs at two areas which were along the ILSAS road and admin building. There was a portion of yellow colour signal been highlight nearby that area too. The green colour signal was highlighted at Murni apartment, $\mathrm{COE}$, and, MPH. Same goes to Ec/No signal the 814 samples was taken, 519 samples are in good quality, 261 samples are in moderate quality, 28 samples are in bad quality and 6 samples are in worst quality. From the generated map, four different colours occur at the route. Majority of the road are in green colour which is good Ec/No signal. There is a small portion of route which having the bad and worst $\mathrm{Ec} / \mathrm{No}$ signal. The areas are same as the RSCP route which having the bad RSCP signal- ILSAS and admin building area. This shown that there is a relationship between RSCP and Ec/No parameter. When the RSCP signal quality is good, the Ec/No signal quality are good, vice versa.

From the data above, it presented in Figure 5 below that the overall performance of Telco A operator in RSCP and Ec/No parameters are considered good.

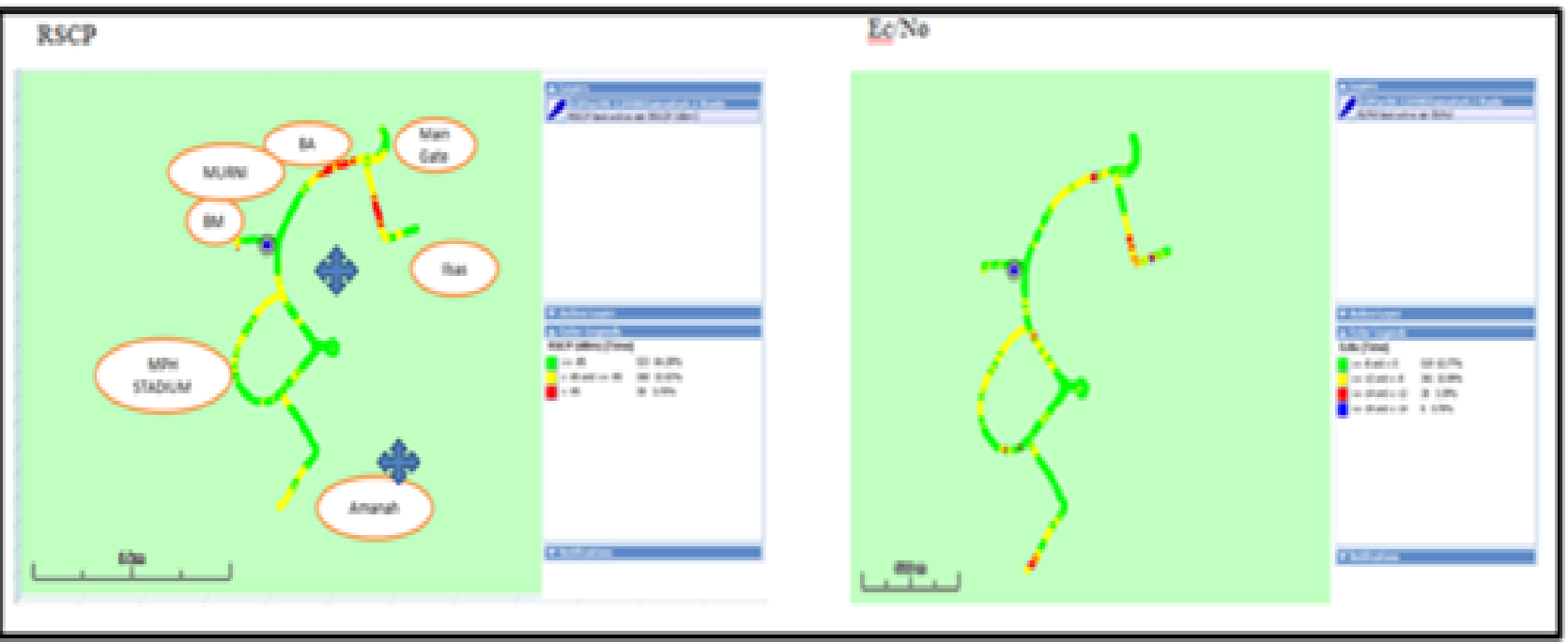

Fig. 5: RCSP and Ec/No signal of telco A operator

\subsection{Telco B}

In this operator, there are 1192 sample of signals been generated during the entire drive test. A $69.97 \%$ is in good quality RSCP signal, $22.40 \%$ is in moderate RSCP signal and only $7.63 \%$ is in bad quality of RSCP signal. This shown that the quality of RSCP parameter is good in Telco B operator. From the generated map, there are different colour been plot along the drive test route. The red colour occurs at entrance of UNITEN-main gate area, admin building area and COIT area. As shown, the COIT area has the worst RSCP value along the drive test route.
Again for Ec/No, the 1191 sample of signals has been generated during the entire drive test. 1023 samples are in good quality, 154 samples are in moderate quality, 8 samples are in bad quality and 6 samples are in worst quality. This data shown that the quality of Ec/No parameter are good since majority of the samples are good quality signals. From the generated map, four different colours occurred at the route. Majority of the road are in green colour which is good Ec/No signal. There is a small portion of route which having the bad and worst Ec/No signal. The areas are same as the RSCP route which having the bad RSCP signal- along the COIT area. Again, it shown that there is a relationship between RSCP and 
Ec/No parameter. When the RSCP signal quality is good, the Ec/No signal quality are good, vice versa.

From the data above, it shows that the overall performance of Telco $\mathrm{B}$ operator in RSCP and Ec/No parameter in Figure 6 below are considered good. And hence the distance between cell site and the receiver also affect the received signal.

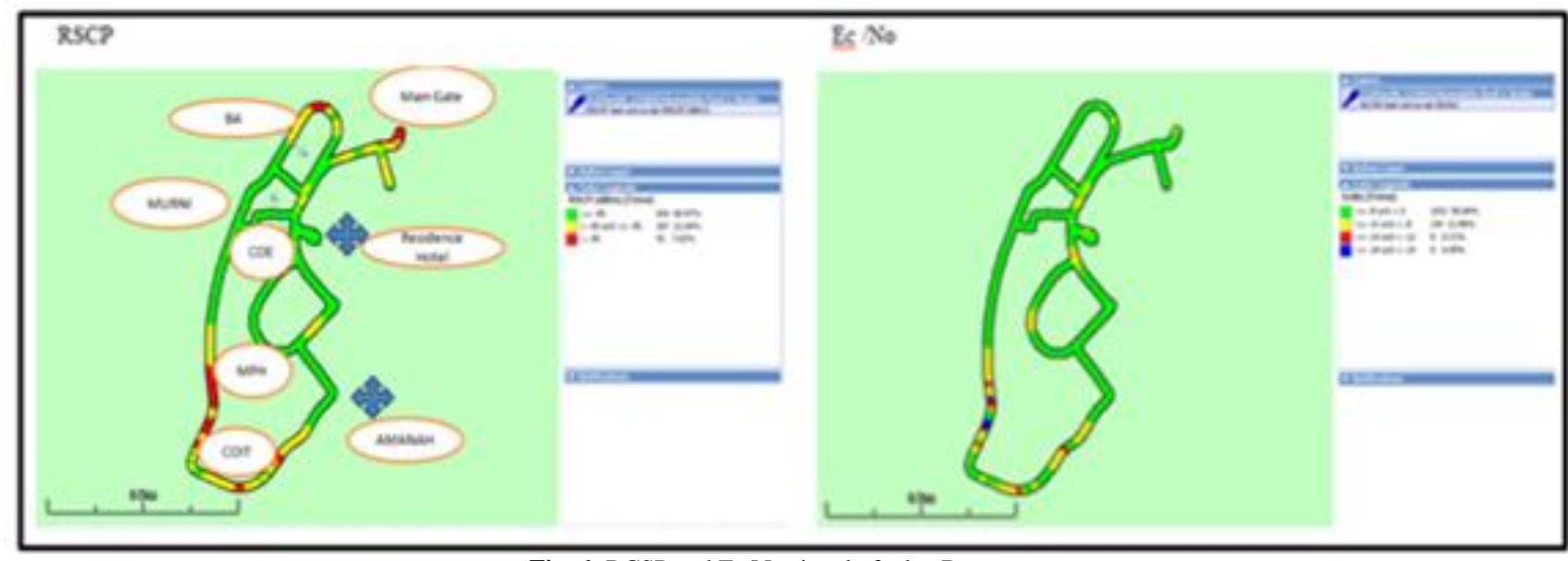

Fig. 6: RCSP and Ec/No signal of telco B operator

\subsection{Telco C}

The 1103 sample of signals been generated during the entire drive test. A $34.06 \%$ is in good quality RSCP signal, $49.70 \%$ is in moderate RSCP signal and only $16.24 \%$ is in bad quality of RSCP signal. This shown that the quality of RSCP parameter is not really good in operator C. From the map, there are different colour been plot along the drive test route. The red colour occurred quite often in the map. This shown that the performance and quality of RSCP is bad in UNITEN area for Telco C operator. Only $20 \%$ of the area is having a better RSCP quality. This indicated that the $3 \mathrm{G}$ coverage for Telco $\mathrm{C}$ in Uniten is under performance.

For Ec/No, in 1102 samples, 511 samples are in good quality, 516 samples are in moderate quality, 43 samples are in bad quality and
32 samples are in worst quality. This data shown that the quality of Ec/No parameter are moderate since the averages of signal are in moderate quality. From the map, four different colours occurred at the route. Majority of the road are in yellow colour which is moderate Ec/No signal. There is a small portion of route which having the bad and worst Ec/No signal. The areas are same as the RSCP route which having the bad RSCP signal- along the COIT area. Again, it shown that there is a relationship between RCSP and $\mathrm{Ec} /$ No parameter. When the RSCP signal quality is good, the Ec/No signal quality are good, vice versa. The overall performance Telco $\mathrm{C}$ operator in Ec/No is average. And for RSCP parameter of Telco $\mathrm{C}$ operator are also bad. Figure 7 shows the areas which have the bad RSCP signal are including COIT area, stadium area and admin building area. Again, the COIT area has the worst coverage for Telco $\mathrm{C}$ operator in $3 \mathrm{G}$ services.

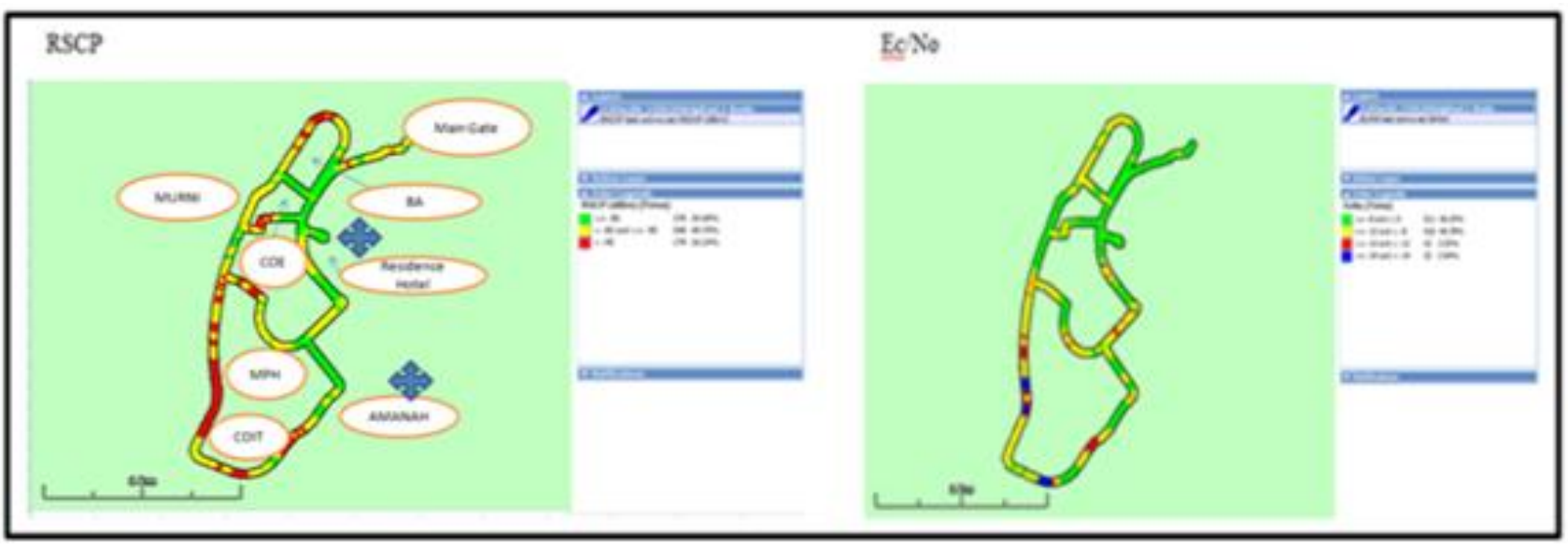

Fig. 7: RCSP and Ec/No signal of telco C operator

\subsection{Telco D}

In this last operator, 242 samples were taken, $57.49 \%$ is in good quality RSCP signal, $14.00 \%$ is in moderate RSCP signal and $28.51 \%$ is in bad quality of RSCP signal. This shown that the quality of RSCP parameter is bad for Telco D operator. From the generated map, there is only a little bit of the route been coloured. The route or the areas which have the colour mean there is $3 \mathrm{G}$ coverage over there. As shown, the RSCP parameter did not exist much for the entire route. This shown that the quality of the RSCP parameter for Telco D is bad. User of Telco D operator has the difficulty to make $3 \mathrm{G}$ phone call and $3 \mathrm{G}$ internets in UNITEN area.
In Ec/No with remain same sample, 44 samples are in good quality, 132 samples are in moderate quality, 29 samples are in bad quality and 37 samples are in worst quality. This data shown that the quality of $\mathrm{Ec} / \mathrm{No}$ parameter are moderate since the averages of signal are in moderate quality. From the generated map, four different colours occurred at the route. The Ec/No signal only exist at a small portion of the route. It is related to the RSCP route. Majority of the signal are in bad and worst quality.

The overall performance of operator D in Ec/No parameter is bad. From the result, Telco D operator provides a bad service for $3 \mathrm{G}$ in UNITEN area as shown in Figure 8. The RSCP and Ec/No parameter need to be tuned in order to provide a better $3 \mathrm{G}$ service. Besides 
that, they need to build a $3 \mathrm{G}$ site in nearby area in order to support this service.

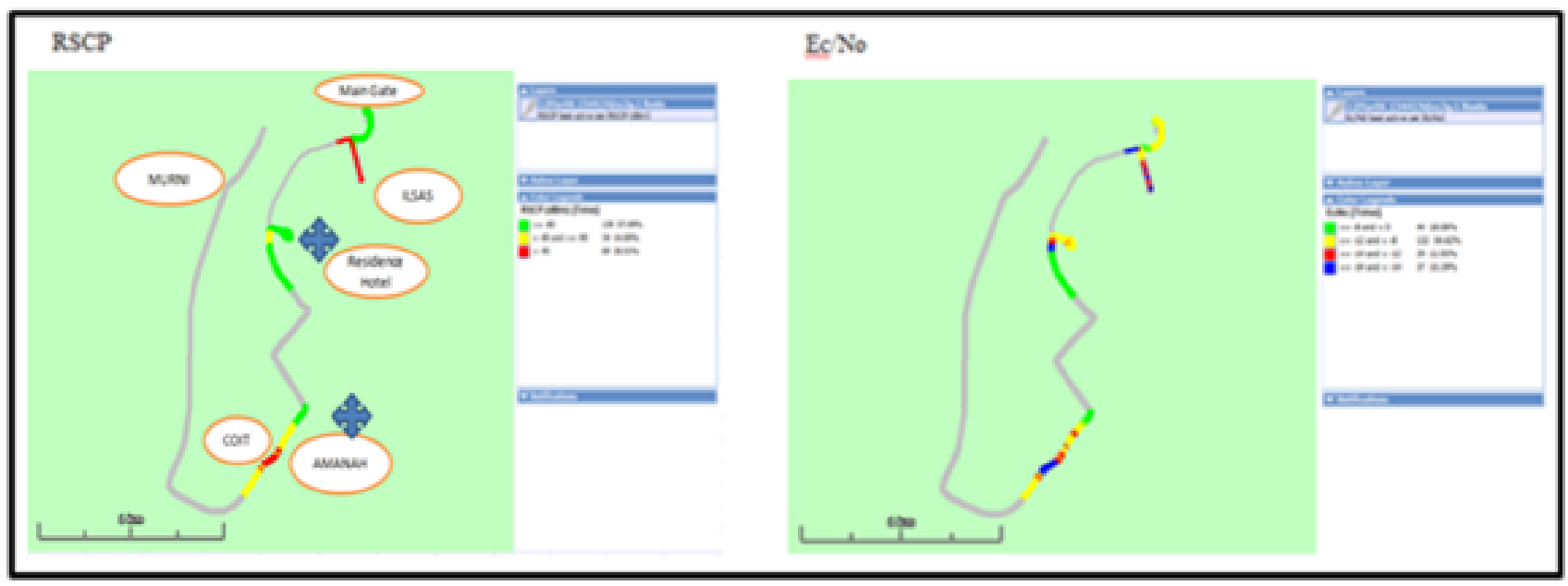

Fig. 8: RCSP and Ec/No signal of telco D operator

\section{Overall Performance}

There are four different operators SIM cards have been carried out for drive test. From the table 2 below, Telco B provided the best $3 \mathrm{G}$ service among the competitor as contained the highest percentage of best RSCP signal which is approximate $70 \%$ compare to others operator. Meanwhile, Telco D is the operator which provides bad $3 \mathrm{G}$ service.

The result is same for Ec/No parameter. Telco B has the highest percentage for $\mathrm{Ec} / \mathrm{No}$ best as $>-8 \mathrm{~dB}$ while Telco D has the lowest percentage for Ec/No best as $>-8 \mathrm{~dB}$. The relationships between RSCP and Ec/No from the Table 2 below were concluded.

Table 2. Relationship between RCSP and Ec/No

\begin{tabular}{|c|c|c|c|c|c|c|c|c|}
\hline \multirow{3}{*}{$\begin{array}{l}\text { Parameter } \quad \text { Operator } \\
\text { RSCP Best As }>=-85 \mathrm{dBm}\end{array}$} & \multicolumn{2}{|c|}{ Maxis } & \multicolumn{2}{|c|}{ Celcom } & \multicolumn{2}{|c|}{ Digi } & \multicolumn{2}{|c|}{ Umobile } \\
\hline & & & & & & & & \\
\hline & $64.28 \%$ & 523 & $57.49 \%$ & 139 & $34.06 \%$ & 376 & $69.97 \%$ & 834 \\
\hline$-85 \mathrm{dBm}>=\mathrm{RSCP}$ Best As $=<-95 \mathrm{dBm}$ & $32.02 \%$ & 260 & $14.00 \%$ & 34 & $49.70 \%$ & 548 & $22.40 \%$ & 267 \\
\hline RSCP Best $A s>=95 \mathrm{dBm}$ & $3.70 \%$ & 30 & $28.51 \%$ & 69 & $16.24 \%$ & 179 & $7.63 \%$ & 91 \\
\hline Ec No Best As $>-8 \mathrm{~dB}$ & $63.77 \%$ & 519 & $18.06 \%$ & 44 & $46.35 \%$ & 511 & $85.84 \%$ & 1023 \\
\hline Eo No Best As $>-12 \mathrm{~dB}$ & $32.09 \%$ & 261 & $54.62 \%$ & 132 & $46.78 \%$ & 516 & $12.96 \%$ & 154 \\
\hline$E c /$ No Best As $>-14 d B$ & $3.39 \%$ & 28 & $11.93 \%$ & 29 & $3.93 \%$ & 43 & $0.71 \%$ & 8 \\
\hline Ec/No Best As $>-30 d B$ & $0.76 \%$ & 6 & 153996 & 37 & $2.94 \%$ & 32 & $0.49 \%$ & 6 \\
\hline $0<=\mathrm{RX}$ Quality $=<2$ & $43.98 \%$ & 222 & $98.23 \%$ & 1174 & & & & \\
\hline $2<=R X$ Quality $=<5$ & $43.00 \%$ & 218 & $1.61 \%$ & 19 & & & & \\
\hline $5<=R X$ Quality $=<7$ & $13.02 \%$ & 66 & $0.17 \%$ & 2 & & & & \\
\hline RX Level $>=75 \mathrm{dBm}$ & $44.76 \%$ & 289 & $87.96 \%$ & 1159 & & & & \\
\hline RX Level $>=-85 \mathrm{dBm}$ & $44.66 \%$ & 301 & $9.94 \%$ & 131 & & & & \\
\hline RX Level $>=95 \mathrm{dBm}$ & $8.58 \%$ & 55 & $1.55 \%$ & 20 & & & & \\
\hline RX Level $>=105 \mathrm{dBm}$ & $0.00 \%$ & 0 & $0.55 \%$ & 7 & & & & \\
\hline
\end{tabular}

\section{Conclusion}

From calculation and test result, it showed that the relationship between RSCP and Ec/No in path loss calculation is directly proportional to each other's. This parameter is easily affected by the distance between the transmitted antenna and receiving mobile antenna. Besides, it also proved that the terrain contour, site environment and antenna height are affected the throughput of the antenna transmitting power for mobile base station.

As a conclusion, this research is succeed since the logfile manage to get and been analyzed. The result has proved that the relationship between the RSCP and Ec/No. The network performance of mobile operators in UNITEN vicinity was analyzed. Further recommendation such as new cell site, antenna angle adjustment and re-planning the RF design has been purpose.

\section{Acknowledgement}

This research work in Universiti Tenaga Nasional (Uniten) and Institute of Sustainable Energy (ISE) is supported and funded by innovation and Research Management Centre under Smart University Research Grant, grant number:- 10289176/SMART/2018/17.

\section{References}

[1] Anite, Nemo Handy http:www.anite.com/anite/en/solutions /nemotesting/ products/nemo_handy

[2] Seybold JS, Introduction to RF propagation, John Wiley and Sons, ISBN 0-471-65596-1, (2005).

[3] Qualcomm, May, 2006 WCDMA Network Planning and Optimization 80-W0853-1

[4] Yi Sheng Zhu (Aug, 2011) An improved mobile location approach based on RSCP difference

[5] Clinth Smith, (1996) Cellular System, McGraw-Hill

[6] Mishira AR, Advanced Cellular Network Planning and Optimization, Wiley, (2004), pp:30. 